\title{
The Effect of Story Reading on Incidental Lexical and Grammatical Collocation Learning ${ }^{1}$
}

Mina Naderi

mina.naderi9018@gmail.com

M.A. in ELT

University of Sistan and Bluchestan

$\&$

Fatemeh Barani

barani.f.4552@gmail.com

M.A. in ELT

University of Sistan and Bluchestan

\begin{abstract}
The purpose of the present study was to investigate the effect of story reading on incidental lexical and grammatical collocation learning. Moreover, it was an attempt to scrutinize whether there was any significant difference between incidental lexical and grammatical collocation learning. To this end, 36 Iranian EFL learners attending Sadra English Institute in Yasuj participated in the study. They were selected based on the result of quick placement test (QPT) as 28 out of 36 elementary EFL learners. A total of 28 learners were assigned into one experimental group $(n=15)$ and one control group $(n=13)$. The result of the pre-test and posttest analysis using One-Way ANCOVA and MANCOVA revealed the fact that there was statistically significant increase in collocation knowledge of the learners. In addition, participants performed significantly on grammatical post-test than lexical post-test after the treatment.
\end{abstract}

Keywords: Incidental Learning-Lexical and Grammatical Collocation-Story Reading

\section{Introduction}

Vocabulary, an indispensable (L2) learners based on the previous studies constituent of language, has constantly been a major area of interest within the field of English language teaching (ELT) as Hammer (1991, p. 153) states "If language structure makes up the skeleton of language, then it is vocabulary that provides the vital organs and flesh." By the same token, it has been generally recognized that much of our vocabulary comprises diverse kinds of prefabricated chunks and shows a tendency to occur in multi-word units (Lewis, 2000; Schmitt, 2010), among which collocations were found problematic for second language (Produromou, 2003; Shehata, 2008; Pei, 2008; Miyakoshi, 2009; Vural, 2010).

There is a consensus among scholars that knowing the essence of language knowledge requires knowing collocational knowledge (Hill, 2000; Ellis, 2003; Shehata, 2008; Lewis, 2010; Alsakran, 2011). As Hill (2001) reported approximately $70 \%$ of language comprises fixed expressions, in which the number of collocations outnumbers that of single-word items. Firth introduced the term collocation in 1957 and defined it as "the company that words keep"

\footnotetext{
${ }^{1}$ This article has been accepted to be published in Beyond Words Vol.8 No.1 May 2020.

DOI: https://doi.org/10.33508/bw.v8i1.2126
} 
(p.183). Two paramount classifications including grammatical and lexical exist for collocation. Benson, et al. (1986, p.10-25) categorize the former into eight types composing of: (1) noun + preposition (apathy towards), (2) noun + to + infinitive (a fool to do),(3) noun + that clause (an agreement that), (4) preposition + noun (on time), (5) adjective + preposition (curious about),(6) adjective + to + infinitive (necessary to work), (7) adjective + that clause (afraid that), (8) verb + preposition (go for) and), and (9) 19 verb pattern types (e.g. base the conclusion on) (as cited in Abedi \& Mobaraki, 2014). The latter is categorized into six types consisting of: (1) verb + noun (launch a missile), (2) adjective + noun (reckless abandon), (3) noun + verb (adjectives modify), (4) noun1+ of + noun2 (a piece of advice), (5) adverb + adjective (deeply religious), (6) verb + adverb (to apologize humbly). Verb-noun type out of the six lexical collocation combinations is found to be the most problematic for L2 learners due to following reasons. First, it could be pertinent to the already known words which learners fail to make appropriate combinations (e.g., make a mistake vs. do a mistake). Second, in addition, lack of semantic distinctiveness (e.g. make rather than do in make an effort) and/or near-synonymous competitors (e.g. tell rather than say in tell lies) cause learners to find it hard when it comes to remembering (Webb, Newton, \& Chang, 2013; Boers et al., 2016).

Ample of studies substantiated reading is a prominent powerful source of both vocabulary acquisition and collocation learning in particular in a second language context, besides, the hypothesis of reading with no explicit instruction results in incidental vocabulary development ( Krashen, 2004; Lehmann, 2007; Lee \& Hsu,
2009; Ponniah, 2009; Yali, 2010; Ramos, 2014). There exist inconsistent views in this regard; on one hand, Swanborn and De Glopper (2002, pp. 95-6) state "during reading, new word meanings are derived and learned even though the purpose is not the learning new vocabulary". On the other hand, Nation (2001; as cited in Richards \& Reynanda, 2002) challenges the incidental approach and proposes a systematic approach.

Debate continues about the optimal pedagogic method for teaching collocation; However, extensive research conducted lends support to varied means of instructions, namely extensive reading accompanied by task-based post-reading activities (Khonamri\& Roostaee,2014; Hu, 2015; Pereyra, 2015; Shabanpour \& Marzban,2015; Boers, Dang, \& Strong, 2016) , collocation in enhanced and unenhanced conditions, e.g. highlighted (bold), non-highlighted and glossed forms (Sonbul\& Schmitt ,2013, Szudarski \& Carter,2016), explicit and implicit instructions (Karami,2013; Kamal,2014). Despite the proliferating evidence in these studies that L2 incidental learning occurs incrementally particularly through extensive reading in input-rich environments, majority of them has further conceded ineffectiveness of just using incidental vocabulary instruction and corroborated the integration of intentional learning, explicit instruction, and addition of text-based tasks into a language course to expand the collocational knowledge. Nonetheless, few studies have targeted the impact of stories, notably novel, as a classroom material on the collocation knowledge of Iranian EFL learners. As a result, the existing study aims at shedding more light on incidental collocation learning by investigating the effect of story reading in a L2 classroom context. Additionally, so far, 
however, no single study has been found that surveyed the difference between lexical and grammatical collocation learning via story reading.

\section{SLA Research on Incidental Collocation Learning}

To date a considerable amount of literature offers intriguing contradictory findings about collocation learning. Reading has consistently been a pivotal source in numerous studies showing a facilitative effect on the incidental acquisition of not only vocabulary but also collocation knowledge. For instance, Shabanpour and Marzban (2015) integrated the instruction of 90 pre-intermediate EFL learners under study with three tasks: fill in-the-blanks, sentence writing, and translation sentences to delve into incidental grammatical collocations learning through reading. Subjects were allocated to three classes randomly completing one of the task complexities. After ten sessions of treatment i.e. reading text followed by five questions, findings showed that there was a significant gain in grammatical collocation knowledge of all three experimental groups. In the same vein, Khonamri and Roostaee (2014) incorporated form versus meaning-focused tasks into an extensive reading (ER) program to study the development of lexical collocations among Iranian Intermediate EFL learners. All the participants $(n=25)$ of this study were assigned to read ten books in different genres. Form-focused task group $(n=11)$ were required to read a book every week outside of the class and to write down the unfamiliar words with their contemporary collocation family examples along with dictionary definitions and the sentences the words were located in, in a notebook. While the meaning-focused task group $(n=14)$ were required to orally present their books to the class after reading each book, and they were asked to fill in a book report form as well. In accordance with that of Shabanpour and Marzban's (2015), the findings in Khonamri and Roostaee's (2014) study confirmed the fact that task-based instruction contributed in learners' collocation development.

Considering a more critical aspect, Boers et al., (2016) put forward a practical recommendation for textbook authors based on the compelling results engendered on the comparison of effectiveness of three fill-inthe-blank exercises among which select the phrase format was found to generate the best result in contrast to the select the verb and first letter cue formats. According to the analysis, almost $85 \%$ of the phrase-focused exercises in contemporary EFL textbooks (e.g. New Headway, Four corners, and English Result) clearly subsume matching and gap-fill exercises. Accordingly, in order to foster good knowledge of L2 multiword units (collocations) in activities embedded in textbooks, the findings of this study alleviate the burden on authors' shoulders but insufficient body of research call for ongoing experimental studies to derive clear and concrete guidelines for the design of phrase focused activities.

An additional important line of collocation investigation encompasses the utilization of stories as a reading material. By way of example, Pereyra (2015) consolidated the ER with lexical approach tasks in a case study to examine the lexical chunks acquisition. Seven adult Spanish speakers with an intermediate English level volunteered to be the participants. Three of them read eight graded reader books. Two of them read one graded reader, journals and one authentic novel, and the other two read diverse texts including journals, magazines 
and short stories. The activities employed were personal and text-focused post-reading activities such as oral book reports, comparing characters in the story and so forth. The conclusion accords with Khonamri and Roostaee's (2014) on that the more the students read the more they learnt. However, as suggested by the author, a wider scope research with control group is needed to measure and accredit, and if, the lexical acquisition would be improved.

Another study focusing on modified versions of a story with 4-8 exposure frequency targets was by Pellicer-Sánchez (2017) in which six adjective-pseudoword collocations inserted throughout the version A and B of the story. Forty-one L2 learners were randomly assigned in version A group (8-repetion) and version B group (4repetition). Participants read the story in a classroom setting and one week afterwards they were individually interviewed about the receptive and productive knowledge of the form and meaning of the collocations. Results revealed form- meaning link of collocational knowledge can be learnt incidentally from story reading; and repetition within 4-8 frequency did not seem to have a significant effect on the acquisition of any of the aspects examined in the study. Surprisingly, on the contrary, Webb, et al. (2013) concluded frequency manipulation between five and 10 encounters in a readingwhile-listening condition to a modified graded reader (i.e. Oxford Bookworms graded reader New Yorkers ) contributed to the incidental learning of 18 collocations and led them to declare that 15 times exposure may be necessary to gain a considerable incidental collocations learning.

In a more comprehensive study carried out by Teng (2016), acquisition of four dimensions of vocabulary knowledge: form recognition, grammar recognition, meaning recall, and collocation recognition in a reading-only vs. reading-while-listening condition was gauged. The Love of a King, a level 2 graded reader for elementary learners published by Oxford University Press, was read aloud by a native English speaker for the learners in the reading-while-listening condition. The results revealed that both conditions could be sources of incidental word acquisition, however, reading-whilelistening condition was more effective than the reading-only condition and exposure frequency and elaborate word processing were needed. In addition, it empirically approved collocation is the most difficult type of vocabulary knowledge than meaning, grammar, and form respectively for the students. Parallels can be drawn between the results observed in Webb, et al.'s (2013) study and Teng's (2016) regarding repetition which in both studies learners benefited from reading and contradicts with that of found by Pellicer-Sánchez (2017).

Similarly, Macis (2018) looked at the literal and figurative meanings of collocations through reading a single semiauthentic novel (i.e. a romantic thriller) that contained 38 Verb+Noun and Adjective+Noun target combinations. Three relatively advanced participants were asked to read Playing Dead, the Prison Break trilogy by Allison Brennan (2008) for pleasure, in their free time and at an appropriate pace. Using dictionary was not allowed. The novel was around 115,000 words long in 462 pages. The results adds to the evidence in current literature that reading semi-authentic texts seeded with the instances of the collocations can enhance the figurative meaning knowledge of duplex collocations. Concerning repetition, however, findings are in congruent with Pellicer-Sánchez's (2017) indicating no significant dependable factor. Likewise, 
Heidari and Naderi (2017) used an authentic novel to probe the incidental collocation learning of 21 upper intermediate English Translation students at university of Sistan and bluchestan and outcomes concurred with Macis's (2018) reinforcing the influential effect of story reading.

Undoubtedly, with little empirical research at disposal on the effectiveness of reading authentic materials in a L2 classroom setting to develop incidental collocation knowledge further investigation is still needed. First reason is that abundant recent studies have mostly employed graded readers in which the target words were substituted with their counterparts in the context to inspect the encounter frequency (Webb, et al., 2013; Pereyra, 2015; Teng, 2016; Pellicer-Sánchez, 2017). Even though graded readers with repeated encounters seem to be influential, text naturalness in term of practicality is brought into question and it has to be acknowledged that other factors also play roles in incidental collocation learning. It has been affirmed that acquiring such vocabulary is a complex and dynamic process which is contingent on several factors including the repetition and salience of such words in L2 input, the exposure amount to English, learning context, and learners' L1 and L2 phraseological differences (Szudarski, 2017). Second important reason involves the nature of the collocation. Using real collocations, as having a higher ecological validity, makes it difficult to control for prior knowledge of the collocation individual components which tends to affect the overall learning gains. Webb et al. (2013) suggested the use of pseudowords to overcome this limitation and eliminate the need to use pre-tests. However, study with a certain collocation typology may not be generalized to other types of collocations learning and teaching (Teng, 2016; Macis, 2018). Last foremost impetus for the current research is reconduction of Heidari and Naderi's (2017) research which lacked a control group.

To address to these issues and fill the void, EFL teachers can provide opportunities by exposing the learners to authentic materials as part of the classroom syllabi. Various advantages for the use of literature in EFL/ESL classes are proposed by scholars which are: an authentic source, improving motivation, cultural/intercultural awareness and globalization development, an intensive/extensive reading practice source, sociolinguistic/pragmatic knowledge development, grammar and vocabulary knowledge promotion, language skills reinforcement, emotional intelligence (EQ) improvement, and fostering critical thinking (Khatib, Rezaei, \& Derakhshan, 2011). Likewise, Teng (2016) justifies this fact according to his teaching experience and indicates "students prefer to read stories because they are interesting and do not require background knowledge to contemplate the text."

Since there seems to be a necessity to conduct a study on collocation learning through story reading (e.g. an authentic novel), this study draws on the following questions: 1) Does story reading have any significant effect on incidental collocation learning? 2) Is there any significant difference between incidental lexical and grammatical collocation learning?

\section{Participants}

\section{Method}

Subjects were chosen through cluster sampling as 36 Iranian EFL learners taking 
Four Corners (FC) $2 \mathrm{C}$ and $3 \mathrm{~A}$ courses at Sadra English institute who all inhabit in Yasuj province, Iran. Descriptive statistics unveiled the age of control group ranged from 12 to 30 and experimental group age ranged from 12 to 24 . Over half of the sample in control group, $76 / 9 \%$, was male $(\mathrm{n}=10)$ and $23 / 1 \%$ was female $(n=3)$. Out of 15 subjects in the experimental group 26/7\% $(n=4)$ was male and $73 / 3 \%(n=11)$ was female. They came from the same language backgrounds in Yasuj.

Although subjects' language proficiency level was determined by a rigorous rater in the institute, QPT version 2, an English language proficiency test developed by Oxford University Press and Cambridge English for Speakers of Other Languages (ESOL), was administered to homogenize and harness their entry behavior based on a single criterion. This version consists of two sections including 60 multiple choice items assessing participants in reading, vocabulary, and grammar. Of the cohort of 36 participants' performance on the test, 28 were assembled as elementary. Four were excluded from the sample on the basis of the degree of their proficiency level (lower- and upper- intermediate) and four dropped out during the research process. They were then randomly assigned to two different leaning condition groups: story reading group and conventional teaching method group. As reported in Table 4.1, the pre-test mean scores of both groups were 3.230 and 3.333 indicating that the collocation knowledge among learners was relatively at the same level.

\section{Reading Material and Target Items}

An authentic novel, The Adventures of Huckleberry Finn by Mark Twain (1805), was chosen as the reading material. Three different softwares: Readability test tool, vocabulary profiler, and Ant Concordancer were utilized to analyze the context of the first ten chapters. According to vocabulary profiler on Compleat Lexical Tutor website, the novel contains 23454 token words and 2413 word types spread across 78 pages. In addition, $84.68 \%$ of the words belongs to the first 1000 word list and $5.37 \%$ to the second 1001-2000 word list. Computed by six readability indices (e.g. Flesch Kincaid Grade Level, Gunning Fog index, and SMOG Index) on WebFX website, average grade level of the text is about 6 and it should be easily understood by 11 to 12 year olds. As revealed by Ant Concordancer software, the highest frequency level was allocated to collocations such as make up one's mind and hair-ball with 5 and 8 times repetition respectively. However, the majority of the target words were merely repeated naturally once or twice throughout the text. The number of the collocations under study which all were extracted from the novel itself were 26 grammatical (e.g. keep an eye on, make up one's mind, run through the audience, find fault with, etc.) and 24 lexical collocations (e.g. downhearted, low-down, low-spirited, cry-baby, etc.)

\section{Instruments}

The target collocations were measured with teacher-made tests: a) a pre-test b) a post-test and to appraise the learners' attitude toward incidental leaning through story reading post-treatment open-ended questions were created.

\section{Teacher-made Pre-test and Post-test.}

The tests measured the productive and recognition knowledge of the collocation written forms. It consists of both fill in the blanks and matching grammatical and lexical collocations items. The first included 26 productive fill in the blanks items in which the learners were required to write the correct nod word (verb) of the provided collocates. 
The second was composed of 24 matching items measuring recognition and production knowledge of the lexical collocation written forms. All the stems of the questions were taken from online Cambridge dictionary. The reliability of the teacher-made pre-test was calculated by Cronbach's Alpha as 0.74 in which it was administrated primarily to 24 upper intermediate EFL learners studying at Farhikhtegan institute of international languages (Heidari \& Naderi, 2017). Both the pre-test and post-test had the same format and to minimize the test effect and maximize incidental learning the students were not informed there would be a post-test. After ten session treatment, the teacher gave the participants the open-ended questions regarding learners' opinions on story reading in the classroom.

\section{Procedure}

The treatment took place during the fall semester of 2018, at Sadra English Institute in four elementary English language classes, namely two FC 2C and 3A. All students attended English classes at least two sessions a week, each one lasting 90 minutes. The objectives of the study were not explained to the participants because it tried to explore the incidental learning of the collocations.

At the very beginning, learners took a teacher-made pre-test. The treatment lasted for 10 consecutive sessions in the story reading group for approximately 30 to 40 minutes and the control group enjoyed the conventional teaching method. Every session nearly one chapter of the story was read by either the teacher or the students were encouraged and consentient to read aloud in the classroom. The students were asked not to use dictionary during the reading process. Furthermore, each session started with warm-up questions to summarize what happened in the previous chapter and to involve students in the plot of the story. Also, since a few participants reported during the treatment that the reading material included some unknown words causing an inability to follow the storyline, and there were a number of dialects such as Missouri negro, extremest form of backwoods Southwestern, and ordinary Pike County, the teacher provided the learners with a list of difficult words definitions (except the target collocations) to increase the comprehensibility of the context of the story. Once the ten session exposure completed, an oral summative test of the whole ten chapters was taken from the students individually to make sure they read the entire chapters. Finally, Post-test and open-ended questions were administered immediately after the oral test. A strict marking system was employed as giving 1 point to correct answers and 0 to incorrect answers.

\section{Results}

The descriptive statistics (mean and collocation variable $(M=9 / 200)$ with its standard deviation) associated with components (grammatical and lexical dependent variables in treatment and control groups are illustrated in Table 4.1 to promote a quantitative and efficacious analysis.

Preliminary obtained results in Table 4.1 revealed that numerical mean score of collocations) in treatment group has developed after post-test indicating an improvement in incidental collocation knowledge. 
Table 1

Descriptive Statistics of Pre-Test and Post-Test

\begin{tabular}{ccccccc}
\hline & & \multicolumn{3}{c}{ Pre-Test } & \multicolumn{2}{c}{ Post Test } \\
\hline Variables & Groups & $\mathbf{N}$ & Mean & Standard Deviation & Mean & Standard Deviation \\
\hline \multirow{2}{*}{ Gram Col } & Control & 13 & $1 / 692$ & $1 / 750$ & $1 / 923$ & $1 / 552$ \\
& Treatment & 15 & $1 / 800$ & $1 / 422$ & $4 / 400$ & $2 / 292$ \\
\hline \multirow{2}{*}{ Lexi Col } & Control & 13 & $1 / 538$ & $2 / 503$ & $4 / 692$ & $2 / 657$ \\
& Treatment & 15 & $1 / 533$ & $1 / 807$ & $4 / 800$ & $2 / 144$ \\
\hline \multirow{2}{*}{ Collocation } & Control & 13 & $3 / 230$ & $3 / 443$ & $6 / 615$ & $3 / 524$ \\
& Treatment & 15 & $3 / 333$ & $2 / 794$ & $9 / 200$ & $2 / 956$ \\
\hline
\end{tabular}

To investigate the efficacy of story reading on incidental collocation learning, the researcher ran One-Way ANCOVA. Results of Kolmogorov-Smirnov and Levene's tests ensured there was no violation

\section{Table 2}

One-Way ANCOVA of Treatment Group and Control Group

\begin{tabular}{lcccccc}
\hline $\begin{array}{l}\text { Variance } \\
\text { Source }\end{array}$ & $\begin{array}{c}\text { Sum of } \\
\text { Squares }\end{array}$ & df & Mean & F & Sig. & Effect Size \\
\hline Post-test & $57 / 371$ & 1 & $57 / 371$ & $6 / 699$ & $0 / 016$ & $0 / 211$ \\
\hline Group & $44 / 764$ & 1 & $44 / 764$ & $5 / 227$ & $0 / 031$ & $0 / 173$ \\
\hline Error & $106 / 214$ & 25 & $564 / 8$ & - & - & - \\
\hline
\end{tabular}

From the table above we can see that the difference between treatment and control groups 'performance with reference to incidental collocation post-test scores of learners in this variable at $95 \%$ level was statistically significant, $F(1,25)=5 / 227, \mathrm{P}$ $=0 / 031<0 / 05, \eta^{2}=0 / 173$. Based on this analysis it can be concluded that the group effect was meaningful which means there was a difference in dependent variable between groups. To evaluate the effect size, Eta squared formula was performed and it of normality assumptions concerning scores distribution and variance homogeneity. Table 2 represents the result of One-Way ANCOVA. yielded $17 / 3 \%$ of the difference was due to independent variable (treatment). Thus, the treatment group in comparison to the control group varies significantly in incidental collocation learning.

The composite nature of the dependent variable (lexical and grammatical) made it possible to run MANCOVA in order to delve further into whether there is any significant difference between lexical and grammatical collocation learning. Prior to conducting MANCOVA, Box's M test was run to check 
the homogeneity assumptions of variancecovariance matrices. The equality assumptions of error variance of both groups for dependent variable was confirmed. The analysis of MANOCOVA is presented in Table 4.3.

\section{Table 4.3}

MANCOVA of Lexical and Grammatical Collocation Learning

\begin{tabular}{ccccccccc}
\hline Effect & $\begin{array}{c}\text { Dependable } \\
\text { Variable }\end{array}$ & $\begin{array}{c}\text { Sum of } \\
\text { Squares }\end{array}$ & df & $\begin{array}{c}\text { Mean } \\
\text { Square }\end{array}$ & F & Sig & $\begin{array}{c}\text { Eta } \\
\text { squared }\end{array}$ & Power \\
\hline Group & Gram Col & 40.035 & 1 & 40.035 & $14 / 664$ & 0.001 & $0 / 379$ & $0 / 975$ \\
\hline & Lexi Col & 0.054 & 1 & 0.054 & $0 / 009$ & $0 / 925$ & $0 / 000$ & $0 / 051$
\end{tabular}

Table 4.3 shows that eliminating the pretest impact on the dependable variables and with respect to obtained $\mathrm{F}$ coefficient, there existed a significant statistical difference in the grammatical component ( $\mathrm{F}=14 / 664$, $\mathrm{P}$ $<0.05)$ between the modified mean scores of participants in pre-test and post-test stages. Thereby, the research question is confirmed and a conclusion which can be drawn is that a meaningful change in the experimental group compared to the control group in the grammatical collocation variable in the posttest was inclined to be the influence of the intervention. Based on the ITA coefficients, the greatest effect was on the grammatical sub-scale, with the effect and difference being equal to 0.379 accounting for $37 / 9 \%$ of the difference in grammatical sub-scale post-scores owing to story reading.

\section{Discussion}

An initial objective of this experimental study was to identify the effectiveness of reading an authentic story The Adventures of Huckleberry Finn on incidental collocation learning. The descriptive statistics and the data analysis demonstrated learners could learn collocations incidentally from reading a novel in the classroom, thus corroborating the findings of much of the reviewed literature that have clearly confirmed the importance of reading in enlarging the collocation knowledge (Webb, et al., 2013 ; Khonamri and Roostaee, 2014; Pereyra, 2015; Shabanpour and Marzban, 2015; Boers et al., 2016; Teng, 2016; Heidari and Naderi, 2017; Pellicer-Sánchez, 2017; Macis, 2018).

The most relevant finding was by Heidari and Naderi (2017) which is in an agreement with that of the current study asserting that reading has commonly been recognized as a crucial source for incidental learning of collocation forms. Even though the results should be interpreted with caution as a result of an absence of a control group which limits how far the results can be generalized. A constructive criticism which can be provoked relates to the effect size of the mean scores that Heidari and Naderi's (2017) study yielded a larger statistical effect size as .686 . One possible corollary finding is the higher the proficiency level, the better the collocation acquisition. One notable difference is a delayed post-test administration in which the results showed no retention over time in Heidari and Naderi's (2017) investigation.

In line with finding of the first research question, Macis's (2018) also accords with the observations, which found a consistently positive effect of reading a semi-authentic novel with one to 25 repetition insertion, although not always statistically significant 
regarding the number of occurrences. A weakness with this argument, however, lies in the level of the collocational knowledge in which Macis's (2018) study was restricted to meaning-recall, on the contrary this study focused solely on the form. Teng (2016) compellingly pointed out that to develop a form meaning link, the first step is building memory of word form which can be achieved incidentally from reading input. The material chosen in both studies was on the basis of the researcher's intuition and learners in posttest open-ended questions reported "I think it's useful because students can learn new words and it improves speaking. I'd like to read a short story in the classroom."

A possible explanation could therefore be comprehensible input and that EFL learners should be exposed to texts which are a little beyond their current reading level (Krashen, 1982). There was no exposure to the target words than the novel read in the classroom which was accompanied by several tasks and also participants said they enjoyed reading such an interesting novel, though a few preferred short stories and different genres including romantic. Overall, results suggest reading story in the classroom context can enhance incidental collocation knowledge given that they were exposed to the receptive skills and from the participants' point of view, they thought it benefits the vocabulary improvement.

The second objective aimed at finding the significant difference between incidental lexical and grammatical collocation learning; contrary to expectations, this study found a significant difference in grammatical subscale compared to the lexical collocations (Table 4.3). In contrast to Heidari and Naderi's (2017) findings, however, no outperformance evidence of grammatical variable was detected. The reported mean of gain score for lexical collocation was higher as 9.381. Remarkably, all earlier studies reviewed so far failed to consider the differing major categories of collocations and focused solely on one restricted type namely, Khonamri and Roostaee (2014), Pereyra (2015), and Pellicer-Sánchez (2017) on lexical typology and Shabanpour and Marzban (2015) on grammatical variable. One single study conducted by Macis (2018) sought to answer whether repetition affects the different grammatical forms of lexical Verb+Noun and Adjective+Noun collocations and not which type was acquired better.

The observed difference can thus be explained in part by proficiency level of the learners, if not the only one, as aforementioned learners with higher English proficiency level tended to read the text more comprehensively than the elementary level. To alleviate the comprehension problem, the teacher had to occasionally illuminate what the text portrayed. With regard to the generalization of the findings due to small sample size, caution must be applied.

\section{Conclusion}

This study gauged the efficiency of story reading in the classroom on incidental lexical and grammatical collocation learning. Because of the lack of a delayed post-test it has not been proven the participants have acquired the collocations incidentally in spite of the fact that their incidental collocation knowledge was enhanced. Moreover, the unanticipated finding was that a significant incidental improvement in grammatical collocation compared to lexical collocation was shown. This study contributed as it extended our knowledge on incidental collocation learning by providing significant data analysis and as it was reported by students in post-test open-ended questions 
they believed they learned different and necessary words in spite of the fact they were unaware of being administered incidental collocation tests.

What emerges from these findings provide important pedagogical implications for developing in EFL language programs as an inclusion of stories preferably with bestliked genres in the classroom syllabus. Shedd \& Duke (2008) suggest useful considerations for teachers: (1) careful selection of texts, (2) open-ended questions, (3) discussions about the book, (4) predictions of what might happen next in the book; and (5) talk that relates the real life experiences to the book. Although this study did not evaluated the word repetition as a variable to pinpoint the precise number that a learner would need to learn a collocation, previous studies have shown repeated encounters in the context are likely to influence L2 collocation growth. To increase the amount of the word occurrences and the extent of the sufficient exposure, therefore, teachers can employ text-based post-reading activities such as oral reports summarizing the incidents in the story to engage learners actively in the comprehension process which as a quid pro quo they do a lot of reading.

The final implication is that it may also be worthy for textbook writers' consideration and designers of instructional materials. Thereby, incorporating some supplementary texts, particularly stories which may bring about more collocation exposure in an authentic language may ultimately result in the incidental collocation learning which has been found problematic for L2 learners.

As a consequence of small sample size, firstly, it is strongly recommended that more research in this field be undertaken. Secondly, it would be a ground breaking work if the levels of collocation knowledge including form, meaning, form-meaning link, and recall be investigated to determine which level cause difficulties for L2 learners. Thirdly, word occurrence has recently been probed in graded readers to examine whether repetition with high and low frequencies affects incidental collocation learning. Thus, it seems this question has remained unanswered at present regarding the authentic reading materials such as novel. Fourthly, since this study was a replication of Heidari and Naderi's (2017) investigation and neither overall language proficiency nor the gender was taken into account as a variable in both studies, it would be worthwhile to examine the learners' collocational competence at different functional levels (beginner, elementary, intermediate, and pre-intermediate learners, advanced) to better understand the connection between collocational competence, language proficiency, and gender.

Lastly, more research on incidental collocation learning under diverse conditions including reading only, reading while listening, and watching movies is required.

\section{References}

Abedi, Z. \& Mobaraki, M. (2014).The

Alsakran, R. A. (2011). The productive and receptive knowledge of collocations by advanced Arabic-speaking ESL/EFL learners (Doctoral dissertation, Colorado State University).

Benson, M., Benson, E., \& Ilson, R. (1986b).The BBI Combinatory Dictionary of English: a guide to word 
combinations. Amsterdam: John Benjamins Publishing Company.

Boers, F., Dang, T. C., \& Strong, B. (2016). Comparing the effectiveness of phrasefocused exercises. A partial replication of Boers, Demecheleer, Coxhead and Webb (2014). Language Teaching Research, 21(3), 362-380.

Ellis, N. C. (2003). Constructions, chunking, and connectionism: The emergence of second language structure. In C. J. Doughty, \& M. H. Long (Eds.), The handbook of second language acquisition. Oxford: Blackwell. DOI: 10.1002/9780470756492.ch4

Firth, J. R. (1957a). Modes of meaning. In J. R. Firth (Eds.), Papers in linguistics, (pp190-215). Oxford: Oxford University Press.

Hammer, J. (1991). The Practice of English Language Teaching, London: Longman.

Heidari, M. \& Naderi, M. (2017). The Effect of Story Reading on Incidental Lexical and Grammatical Collocation Learning and Retention by Iranian EFL Learners (Master's thesis). University of Sistan and Bluchestan, Zhedan.

Hill, J. (2000). Revising priorities: from grammatical failure to collocational success. In M. Lewis (Ed.), Teaching Collocation: Further Development in the Lexical Approach. Hove, UK: Language Teaching Publications.

Hill, J. (2001). Revising priorities: From grammatical failure to collocational success. In M. Lewis (Ed.), Teaching collocation: Further developments in the lexical approach (pp. 47-69). Hove, UK: Language Teaching Publications.

Hu, H. M. (2015). The effects of different tasks on verb-noun collocation learning. The Asian Journal of Applied Linguistics, 2(3), 213-225.
Kamal, O. H. (2014). Investigating the effect of explicit and implicit instruction on the acquisition of verb + nouncollocations: a case of L2 Egyptian learners (Master's thesis). School of Humanities and Social Sciences, The American University in Cairo.

Karami, M. (2013). Exploring effects of explicit vs. implicit teaching of collocations on the writing performance of Iranian EFL learners. International Journal of Language Learning and Applied Linguistics. 4 (4), 197-215

Khatib, M., Rezaei, S., Derakhshan, A. (2011). Literature in EFL/ESL Classroom. English Language Teaching Journal, 4(1), 201-208.

Khonamri, F., \& Roostaee, S. (2014).The Impact of Task-based Extensive Reading on Lexical Collocation Knowledge of Intermediate EFL Learners. Procedia- Social and Behavioral Science, 136, 265-270.

Krashen, S. (1982). Principles and Practice in Second Language Acquisition. California: Pergamon Press Inc.

Krashen, S. (2004). Applying the comprehension hypothesis: Some suggestions. The International Journal of Foreign Language Teaching, 1(1), 21-29.

Lee, S. Y., \& Hsu, Y. (2009). Determining the crucial characteristics of extensive reading programs: The impact of extensive reading on EFL writing. The International Journal of Foreign Language Teaching, 5(1), 12-20.

Lehmann, M. (2007). Is intentional or incidental vocabulary learning more effective? The International Journal of Foreign Language Teaching, 3(1), 2328.

Lewis, M. (2000). Language in the lexical approach. In M. Lewis (Ed.), Teaching 
collocation: Further developments in the lexical approach (pp. 126-154). Croatia: Thomson \& Heinle.

Lewis, M. (2010). Teaching collocation: Further developments in the lexical approach. TESL-EJ, 14(2).

Macis, M. (2018). Incidental learning of duplex collocations from reading: Three case studies. Reading in a Foreign Language, 30 (1), 48-75.

Miyakoshi, T. (2009). Investigating ESL learners' lexical collocations: The acquisition of verb+noun collocations by Japanese learners of English (Doctoral dissertation). University of Hawai 'i, Manoa.

Nation, I. S. P. (2001). Learning Vocabulary in Another Language. Cambridge: Cambridge University Press

Pei, C. (2008). Review of empirical studies on collocations in the field of SLA. CELEA Journal, 31(6), 82.

Pellicer-Sánchez, A. (2015). Learning L2 collocations incidentally from reading. Language Teaching Research, 21(3), 381-402.

Pereyra, N. (2015). Extensive Reading in Enhancing Lexical Chunks Acquisition. The Reading Matrix: An International Online Journal, 15(2), 218-234.

Ponniah, R. J. (2009). The robustness of free reading in second and foreign language education. Language in India, 9(12), 2129.

Produoromo, L. (2003). Idiomaticity and the non-native speaker. English Today, 19(2), 42-48.

Ramos, F. D. R. (2014). Incidental vocabulary learning in second language acquisition: a literature review. Profile Issues in Teachers' Professional Development, 17(1), 157-166.

Richards, J. C., \& Reynanda, W. A. (Ed.). (2002). Current Research and Practice in Teaching Vocabulary. Methodology in Language Teaching: An Anthology of Current Practice (pp.256, 258-259). United Kingdom: Cambridge University Press.

Schmitt, N. 2010. Researching Vocabulary: A Vocabulary Research Manual. Basingstoke: Palgrave Macmillan.

Shabanpour, M., \& Marzban, A. (2015). The Effect of Task Complexity on Iranian Preintermediate EFL Learners' Incidental Learning of Grammatical Collocations through Reading. Theory and Practice in Language Studies, 5, 590-597.

doi:http://dx.doi.org/10.17507/tpls.0503 .19

Shedd, M.K., \& Duke, N. K. (2008). The power of planning: developing effective read-alouds. Beyond the journal: young children on the web, 63(6), 22-27.

Shehata, A. K. (2008). L1 Influence on the Reception and Production of Collocations by Advanced ESL/EFL Arabic Learners of English (Master's thesis). Ohio University, Athens.

Sonbul, S., \& Schmitt, N. (2013). Explicit and implicit lexical knowledge: acquisition of collocations under different input conditions. Language Learning, 63(1), 121-159. https://doi.org/10.1111/j.1467-

9922.2012.00730.x

Swanborn, M. S. L., \& De Glopper, K. (2002). The impact of reading purpose on incidental word learning from context. Language Learning, 52(1), 95117.

Szudarski, P. (2017). Learning and Teaching L2 Collocations: Insights from Research. TESL Canada Journal/Revue TESL Du Canada, 34(3), 205-216. http://dx.doi.org/10.18806/tesl.v34i3.12 80 
Szudarski, P., \& Carter, R. (2016). The role of input flood and input enhancement in EFL learners'acquisition of collocations. International Journal of Applied Linguistics, 26(2), 245-265. https://doi.org/10.1111/ijal.12092

Teng, F. (2016). Incidental vocabulary acquisition from reading-only and reading-while-listening: a multidimensional approach. Innovation in Language Learning and Teaching, 12(3), 274-288.

Vural, E. (2010). Explicit and incidental teaching of English verb-noun collocations in an EFL context (Doctoral dissertation). Anadolu University, Eskişehir, Turkey. Retrieved from https://tez.yok.gov.tr/UlusalTezMerkezi Webb, s. Newton, J. Chang, A. (2013). Incidental Learning of Collocation. Language Learning, 63 (1), 91-120.

Yali, G. (2010). L2 vocabulary acquisition through reading-incidental learning and intentional learning. Chinese Journal of Applied Linguistics, 33(1), 74-93. 